\title{
Cover crops and pruning in Bobal and Tempranillo vineyards have little influence on
}

\section{grapevine nutrition}

\author{
Pedro Pérez-Bermúdez ${ }^{*}$, Manuel Olmo², Jaime Gil², Lorenzo García-Férriz ${ }^{3}$, Carmen Olmo ${ }^{4}$, Rafael Boluda ${ }^{1}$, Isabel Gavidia ${ }^{1}$
}

IUniversity of Valencia-Dept. of Plant Biology, Av. V.A. Estellés, s/n - 46100 - Burjassot, Valencia - Spain. ${ }^{2}$ Sierra Norte Winery, C/ del Transporte C2 - 46340 Requena, Valencia - Spain.

${ }^{3}$ Agricultural Processing Company 212 C.V. Fuenteseca 46330 - Camporrobles, Valencia - Spain.

${ }^{4}$ Cajamar - Food-Agricultural and Cooperative Bussiness, Plaza de Barcelona, 5 - 04006 - Almería - Spain.

${ }^{*}$ Corresponding author <perezb@uv.es>

Edited by: Richard L. Mulvaney

Received January 22, 2015

Accepted October 06, 2015

\begin{abstract}
Cover crops may improve vineyard soil properties, grapevine nutrient status and berry composition, however, factors such as cover crop type, annual rainfall, climate and irrigation may change their effects on vineyards. From 2008 to 2011, the effects of a non-permanent cover crop and two pruning techniques on soil as well as vine nutrients and grapevine performance of two vineyards (cv. Tempranillo and cv. Bobal) were evaluated. For that purpose, two legumes were sown in inter-rows of hand-pruned vines in February and were tilled at flowering. Soil tillage, or cover cropping, was combined with either light pruning or severe pruning to study foliar nutrient variations. Soil N, P, K and total organic carbon (TOC) were determined in samples taken from the Ap1 horizon in January prior to vine pruning. Foliar N, P, K contents were measured in leaves sampled upon grape veraison. The differences between vineyards with cover cropping and bare soils suggest that legumes positively affected soil N (1.55 vs. $1.68 \mathrm{~g}$ $\mathrm{kg}^{-1}$ and 1.49 vs. $1.76 \mathrm{~g} \mathrm{~kg}^{-1}$ in Bobal and Tempranillo vineyards, respectively) and soil organic matter (SOM) (12.5 vs. $15.5 \mathrm{~g} \mathrm{~kg}^{-1}$ and 12.9 vs. $17.2 \mathrm{~g} \mathrm{~kg}^{-1}$ in Bobal and Tempranillo vineyards, respectively). The use of cover crops did not affect grapevine yields nor quality of Bobal and Tempranillo berry . Cover crops, or light pruning, did not alter the foliar N, P, K contents of both cultivars since their concentrations were similar to those found in the leaves from vineyards with soil tillage or severe pruning.

Keywords: Vitis vinifera, foliar macronutrients, legumes, soil macronutrients
\end{abstract}

\section{Introduction}

Cover cropping is a management practice used worldwide which can affect soil properties, water and mineral status, organic matter contents and microbiological function in soils (Celette et al., 2009; Guerra and Steenwerth, 2012; Peregrina et al., 2014). Various experiments have tested the effects of cover crops on grapevine performance, mainly in regions with summer rainfall, and have reported positive results because of competition for nutrients and water. Water stress reduces vegetative growth, which enhances fruit exposure and composition (Monteiro and Lopes, 2007) and increases the content of aromatic compounds (Xi et al., 2011). Nevertheless, some studies have reported that cover crops do not affect vine nutrition and yield (Steenwerth et al., 2013) nor alter grape quality (Sweet and Schreiner, 2010). Under dry conditions, fierce competition for water and nutrients, especially N (Celette and Gary, 2013), occurs between vines and cover crops, which can reduce vine growth and yield (Tesic et al., 2007).

Another important management practice in vineyards is pruning. Several works have reported that light pruning not only increases yield, but it also reduces management costs compared to severe manual pruning (Archer and Schalkwyk, 2007; Main and Morris, 2008; Pérez-Bermúdez et al., 2015; Reynolds and Wardle, 2001). Some works also report that light pruning leads to the production of smaller bunches and berries, which may change grape and wine characteristics. Light pruning effects vary according to environmental conditions and vine vigor (Clingeleffer, 2010). However, very few studies have evaluated the influence of pruning on vine nutrient status. Vines subjected to minimal or light pruning and with significantly increased yields could present nutritional stress since grape clusters are important phloematic sinks for organic and mineral nutrients. The combined use of a non-permanent $\mathrm{N}$-fixer cover crop could help overcome nutritional deficits, particularly $\mathrm{N}$, which cannot be supplied through fertirrigation to vineyards for wine production from an ecological perspective.

In this study, the Bobal and Tempranillo vineyards were subjected to traditional tillage, or cover cropping, and severe or light pruning. The objective of this study was to investigate: i) the effects of a non-permanent cover crop on soil macronutrients and on the viticultural performance of grapevines; ii) the impact of soil tillage/ cover cropping, combined with light/severe pruning, on vine nutrient status.

\section{Materials and Methods}

\section{Study site}

From 2008 to 2011, the tests reported in this study were conducted in a commercial winery in Camporrobles (Valencia, Spain, 39³9' N, 1²4' W, 980 m above sea level) in the D.O. Utiel-Requena area. This industrial winery is adapting all the aspects of sustainable measures in winegrowing to produce ecological wines.

Two vineyards (Vitis vinifera L.), with varietals Bobal or Tempranillo grafted on Richter 110, were cho- 
sen for this study. Bobal is an autochthonous grape variety that covers more than $70 \%$ of the total grapevine area in D.O. Utiel-Requena (Valencia, Spain). Bobal and Tempranillo vineyards were planted in 1997 . Vines were spaced $1.35 \mathrm{~m} \times 2.85 \mathrm{~m}$ at a density of approx. 2500 vines $\mathrm{ha}^{-1}$. Spur-pruned grapevines were trained in permanent bilateral cordons. Vines received drip irrigation merely to avoid water deficits and the total volume of water per vine amounted to approximately 180-240 L distributed as three/four irrigations per year. Grapevines were not fertilized during the experiment.

In both vineyards, soils are haplic Calcisols (FAO, 2014) with a profile type Ap Bwk Ck (soil depth ca.70-80 $\mathrm{cm})$ and are mostly calcareous given the characteristics of the parent material $(\mathrm{pH}=7.9-8.4)$. The Tempranillo plots had a clayey texture, which was clayey-loamy in the Bobal parcels. These soils in this Mediterranean region present low fertility, however, good adaptability for grapevine growth. Both vineyards showed strong consistency and subsoil compaction below $20 \mathrm{~cm}$ due to agricultural practices. The average annual air temperature ranged from $12.0{ }^{\circ} \mathrm{C}(2010)$ to $13.3{ }^{\circ} \mathrm{C}$ (2011), whereas annual total precipitation ranged from $353 \mathrm{~mm}$ (2009) to $596 \mathrm{~mm}$ (2010). From 2008 to 2011, the minimum and maximum temperatures were $-10.3{ }^{\circ} \mathrm{C}$ (December, 2010) and $38.9{ }^{\circ} \mathrm{C}$ (July, 2009), respectively. The frost risk period extended for seven months, from October to April, and did not affect the grapevine growth cycle. The climate is Mediterranean with continental influence and dry sub-humid (Thornthwaite climate classification). The water deficiency period in the site lasted from July to September, whereas soil water surplus occurred only in February and March (annual evapotranspiration = $723 \mathrm{~mm}$, summer evapotranspiration $=380 \mathrm{~mm}$ ). The soil temperature regime is Mesic, whereas the soil moisture regime is Xeric (Roca-Pérez et al., 2005). The annual weather conditions in the study site are summarized in Table 1.

\section{Experiment description}

An experimental plot (replication) consisted of five vine rows and six inter-rows. Various experimental plots were delimited in the Bobal and Tempranillo vineyards for each cultivar and treatment, as follows: Treatment

Table 1 - Weather conditions (2008-2011) in study site. Annual total precipitation $(\mathrm{mm})$ and air temperatures $\left({ }^{\circ} \mathrm{C}\right)$.

\begin{tabular}{lrrrr}
\hline & 2008 & 2009 & 2010 & 2011 \\
\hline Total Rainfall & 577 & 353 & 596 & 355 \\
Tavg & 12.5 & 13.2 & 12.0 & 13.3 \\
Avg Tmax & 19.4 & 20.8 & 19.0 & 20.6 \\
Abs Tmax & 37.6 & 38.9 & 36.8 & 36.4 \\
Avg Tmin & 5.9 & 5.9 & 5.8 & 6.6 \\
Abs Tmin & -8.3 & -9.2 & -10.3 & -9.8 \\
\hline
\end{tabular}

Tavg - average temperature, Avg Tmax - average maximum temperature, Abs Tmax - absolute maximum temperature, Avg Tmin - average minimum temperature, Abs Tmin - absolute minimum temperature.
1: Mechanical light pruning (MP) + leguminous cover crop (LCC), Treatment 2: MP + traditional tillage (TT), Treatment 3: Traditional severe pruning (TP) + LCC, Treatment 4: TP + TT. To study the effect of alleyway cover crops on soil macronutrients, vine yield and grape characteristics, we used only the Bobal and Tempranillo experimental plots with Treatments 3 and 4. First, the aim was to evaluate the impact of a non-permanent $\mathrm{N}$ fixer on soil nutrients without possible interactions with the pruning technique. Treatments 3 and 4 were used in this study to determine whether cover cropping had any influence on vine productivity and grape juice quality, given the effects of severe/light pruning on yield and quality of grapevines Bobal and Tempranillo (Pérez-Bermúdez et al., 2015). To study foliar nutrient variations, traditional soil tillage and cover cropping were combined in both vineyards with light mechanical or traditional severe pruning (Treatments 1-4).

In the plots with cover crops, a 50/50 mixture of two legumes (Vicia sativa L. and Vicia ervilia L.) was sown in the grapevine inter-row in late February or early March at a seeding density of $80 \mathrm{~kg} \mathrm{ha}^{-1}$. Legumes were incorporated into the soil when they reached flowering. Legumes were selected as cover crops because they are $\mathrm{N}$-fixers and have a lower $\mathrm{C}: \mathrm{N}$ ratio than grasses do, which is associated with faster decomposition rates after incorporation into the soil (Fourie et al., 2006).

In traditional pruning, 85-90 \% of vine annual growth (dry canes) was removed, and six to eight twobud spurs (approx. 12-16 buds/vine) were retained per vine. Light pruning was firstly carried out with a tractor equipped with a Disco pre-pruner. Then, damaged spur tips were manually pruned and touched up. In light pruning, 10-12 longer spurs, with four buds per spur, were retained on each vine (approx. 40-48 buds/vine). The Bobal and Tempranillo vines were pruned at the end of January when the pruned canes from each grapevine were removed and individually weighed on a hanging scale. Pruned wood was crushed, returned to the vineyards and then incorporated into the soil.

For the analyses of grapes and must, berries from both cultivars were hand-picked during the first two weeks of October (2008 to 2011), the most appropriate time for grape harvesting in terms of sugar content, color and $\mathrm{pH}$. The values used to determine the grape sampling thresholds were: ${ }^{\circ}$ Brix: $19-23$, color intensity: $>8$ for Bobal or $>7$ for Tempranillo, $\mathrm{pH}$ : 3.3-3.6.

\section{Macronutrient analyses in soils and leaves}

We initially determined $\mathrm{N}, \mathrm{P}, \mathrm{K}$ and organic $\mathrm{C}$ in soil horizons Ap1 (0-15 cm), Ap2 (15-30 cm), Bwk (30$55 \mathrm{~cm}$ ) and $\mathrm{Ck}(55-75 \mathrm{~cm})$. The results (data not shown) showed that further soil samplings from the Bobal and Tempranillo vineyards were limited to Ap1 since the highest nutrient contents, mainly $\mathrm{P}$ and $\mathrm{K}$, accumulated in this horizon.

Soil samples were collected prior to vine pruning at the beginning of January from hand-pruned Bobal or 
Tempranillo vineyards, either with or without leguminous cover crops. For analytical determination of exchangeable $\mathrm{K}$, total $\mathrm{N}$, total organic carbon (TOC) and available $\mathrm{P}$, a sample consisting of three sub-samples was taken from each of three grapevine inter-rows situated in the plot center. The sample from an inter-row was considered a replication unit. For the statistical analysis, there were three replicates per treatment, cultivar and year.

Soil samples were air-dried, ground and sieved through a $2-\mathrm{mm}$ mesh. $\mathrm{C}$ content and total $\mathrm{N}$ were determined by the combustion analyses with an elemental analyzer. TOC was calculated by the difference between total $\mathrm{C}$ determined with an elemental analyzer and inorganic C estimated by the ISO (1995) method. Spectrophotometry was used to determine available $\mathrm{P}$, which was extracted with sodium bicarbonate (0.5 M, pH 8.5) as proposed by Olsen et al. (1954). P contents were determined by spectrophotometry according to the Merck protocol and test kit 14842. Exchangeable K was extracted with 0.1 M barium chloride solution (ISO, 1994) and its concentration was measured by atomic absorption spectrometry. All the analytical measurements were performed in triplicate.

The evolution of leaf nutrient contents in vines was monitored as proposed by Navarro et al. (2008). Bobal and Tempranillo leaves were sampled at the end of July, when grape veraison started. For analytical determinations of $\mathrm{N}, \mathrm{P}, \mathrm{K}$, three central vine rows of each experimental plot were selected to obtain three samples per treatment, cultivar and year. Each sample resulted from mixing 20 leaves, collected from 10 selected vines (two leaves of opposite orientation per vine). Leaves were surface-washed, dried and pulverized. Leaf samples ( $1 \mathrm{~g})$ were treated with $\mathrm{HNO}_{3}(10 \mathrm{~mL})$ in a block digester $\left(240{ }^{\circ} \mathrm{C}\right)$ until complete digestion for approximately $4 \mathrm{~h}$. Foliar extracts were filtered and diluted up to $50 \mathrm{~mL}$ prior to the nutrient analysis. $\mathrm{K}$ was measured by atomic absorption spectrometry whereas phosphorus determinations were made by spectrophotometry. The untreated pulverized leaves were used to determine total $\mathrm{N}$ content by the combustion analyses with an elemental analyzer. All the analytical measurements were performed in triplicate.

\section{Grape characterization}

As mentioned above, in order to study the effect of cover crops on grapevine performance, we used only the experimental plots in Treatments 3 and 4. For the sampling and analytical determinations, 15 vines over the three central rows were selected per cultivar and treatment. For the statistical analysis, the five vines/ row chosen for the analytical determinations were considered a replication unit, in other words, three replicates per treatment, cultivar and year. Total yield per vine (fruit weight) and total number of clusters per vine were recorded at harvest. These yield data were used to calculate the mean weight of the Bobal or Tempranillo clusters. The mean berry weight was determined by selecting grapes randomly from different clusters (three replicates per treatment, cultivar and year, with 100 berries each). Berry samples were representative of all the cluster positions and all the positions within the cluster. Immediately after each harvest, the juice of pressed berries (100 berries) was used to perform the chemical analyses. The basic chemistry $\left({ }^{\circ} \mathrm{Brix}, \mathrm{pH}\right.$, color, titratable acidity and polyphenol index) for each grape sample was determined by Fourier-transform infrared spectrometry. For more analytical details, see Pérez-Bermúdez et al. (2015).

\section{Statistical analysis}

The data presented in the tables are arithmetic means and details on the replication units as well as the number of replicates are provided above in this section. The effects of cover crops and pruning methods on the different analyzed parameters were evaluated by the analysis of variance (ANOVA) followed by the t-test $(p<0.05)$ performed on independent samples. All the analyses were performed using the SPSS statistics 17.0.2 software package.

\section{Results and Discussion}

Effect of cover crops in the grapevine inter-rows on soil macronutrients and the viticultural performance of Bobal and Tempranillo grapevines

Two Vicia species were used for cover cropping and a soil management system in the vineyards to assess their effects on mineral nutrition, especially on soil $\mathrm{N}$ and organic matter contents as well as on vineyard yield and grape characteristics.

Nutrient contents found in the Ap1 horizon and their variation ranges during the 2008-2011 period are shown in Table 2. After four years, the only significant difference between leguminous cover cropping and traditional tillage in the Bobal vineyard was the cover-cropped plots with a higher total organic carbon amount (TOC, $15.5 \mathrm{~g} \mathrm{~kg}^{-1}$ vs. $12.5 \mathrm{~g} \mathrm{~kg}^{-1}$ ). In the Tempranillo vineyard soil, both $\mathrm{N}$ and TOC increased at the end of the trials $\left(\mathrm{N}, 1.76 \mathrm{~g} \mathrm{~kg}^{-1}\right.$ vs. $1.49 \mathrm{~g} \mathrm{~kg}^{-1}$; TOC, $17.2 \mathrm{~g} \mathrm{~kg}^{-1}$ vs. $12.9 \mathrm{~g} \mathrm{~kg}^{-1}$ ), suggesting a positive effect of legumes on these parameters. Accordingly, Steenwerth and Belina (2008a, b) used a Chardonnay vineyard to study the effects of cover crops and cultivation on soil $\mathrm{C}$ and $\mathrm{N}$ dynamics. The authors showed that cover crops could affect soil properties and structure, increasing populations of microorganism and $\mathrm{N}$ mineralization, in addition to augmenting SOM. $\mathrm{K}$ and $\mathrm{P}$ contents (Table 2) remained virtually unchanged in both vineyards with cover cropping. The values observed for all these four macronutrients in the Bobal and Tempranillo vineyards were low and fell within the ranges previously described for natural Calcisols surrounding the study area (Roca-Pérez et al., 2005). 
Table 2 - Effect of leguminous cover cropping (2008-2011) on nitrogen, available phosphorous, exchangeable potassium and total organic carbon (TOC) contents in the Ap soil horizons $(0-15 \mathrm{~cm})$ of Bobal and Tempranillo vineyards. Data are the mean values of three replications. For each cultivar and nutrient, the mean values followed by the same letter are not significantly different $(p<0.05)$.

\begin{tabular}{|c|c|c|c|c|c|}
\hline \multirow{2}{*}{ Bobal } & \multirow{2}{*}{$\frac{2008}{\text { initial nutrient status }}$} & \multicolumn{2}{|c|}{2011} & \multicolumn{2}{|c|}{ 2008-2011 (variation ranges) } \\
\hline & & without cover crop & with cover crop & without cover crop & with cover crop \\
\hline $\mathrm{N}\left(\mathrm{g} \mathrm{kg}^{-1}\right)$ & $1.49 \mathrm{a}$ & $1.55 \mathrm{a}$ & $1.68 \mathrm{a}$ & $1.51-1.62$ & $1.49-1.78$ \\
\hline $\mathrm{P}_{2} \mathrm{O}_{5}\left(\mathrm{mg} \mathrm{kg}^{-1}\right)$ & $103 \mathrm{a}$ & $102 \mathrm{a}$ & 113 a & $92-113$ & $100-117$ \\
\hline $\mathrm{K}\left(\mathrm{cmol}^{(+)} \mathrm{kg}^{-1}\right)$ & $1.07 \mathrm{a}$ & $1.06 \mathrm{a}$ & $1.29 \mathrm{a}$ & $0.90-1.08$ & $0.88-1.39$ \\
\hline TOC $\left(\mathrm{g} \mathrm{kg}^{-1}\right)$ & $10.5 \mathrm{a}$ & $12.5 \mathrm{a}$ & $15.5 b$ & $11.1-15.2$ & $13.5-16.3$ \\
\hline Tempranillo & initial nutrient status & without cover crop & with cover crop & without cover crop & with cover crop \\
\hline $\mathrm{P}_{2} \mathrm{O}_{5}\left(\mathrm{mg} \mathrm{kg}^{-1}\right)$ & $100 \mathrm{a}$ & $97 \mathrm{a}$ & $110 \mathrm{a}$ & 75-101 & 79-134 \\
\hline $\mathrm{K}\left(\mathrm{cmol}^{(+)} \mathrm{kg}^{-1}\right)$ & $1.67 \mathrm{a}$ & $1.65 \mathrm{a}$ & $1.80 \mathrm{a}$ & $1.49-1.71$ & $1.59-2.00$ \\
\hline TOC $\left(\mathrm{g} \mathrm{kg}^{-1}\right)$ & $11.0 \mathrm{a}$ & $12.9 \mathrm{a}$ & $17.2 \mathrm{~b}$ & $9.2-15.6$ & $15.2-17.9$ \\
\hline
\end{tabular}

At harvest, the effects of cover cropping, or traditional tillage, on the Bobal and Tempranillo vine yields were evaluated (Table 3). The use of a non-permanent legume cover crop in these vineyards did not affect the viticultural performance of Bobal and Tempranillo grapevines since the four evaluated parameters (total fruit and number of clusters per vine, and mean weights of clusters and berries) remained unchanged in both cultivars with either tillage or cover cropping. An identical response, no difference, was observed when we evaluated the influence of tillage or cover cropping on berry characteristics since ${ }^{\circ} \mathrm{Brix}, \mathrm{pH}$, color, titratable acidity and polyphenol index remained unaffected in both grape varietals over the four-year experiment (Table 3).

Our results corroborate Sweet and Schreiner (2010), who reported that the use of seven cover crops treatments in Pinot noir vineyards did not drastically change water and nutrient status. The authors also observed very little competition between cover crops and grapevines and reported no consistent effect of this practice on neither vine yield nor quality components of grape juice. Steenwerth et al. (2013) reported similar results in their evaluation of five combined treatments of cover crops and tillage in a mature Merlot vineyard from 2008 to 2010. The authors found no differences in soil nutrient availability between treatments and minimal variations in the nutritional constituents of leaf petioles and blades. They concluded that cover crops and/or no-till practices might be implemented in an irrigated vineyard with little immediate effect on grape productivity. In contrast, some authors have reported the positive effect of cover cropping on grapevines with water limitations, because of competition for nutrients and water resources. Water stress hinders plant growth and increases fruit exposure, which enhances juice characteristics and even wine aromatic compounds (Caspari et al., 1997; Monteiro and Lopes, 2007; Xi et al., 2011). The devigorating effect of cover crops on vines has been successfully used as a tool to correct high-vigor situations of some vineyards (see Guerra and Steenwerth, 2012).
Table 3 - Influence of leguminous cover cropping on Bobal and Tempranillo yields and grape characteristics. Data refer to the mean values of four years (2008 to 2011) with three replications per harvest, where five vines/row were considered a replication unit. For each cultivar and parameter, the means with the same letter are not significantly different (t-test level $p<0.05$ ). ${ }^{*}$ Yield variation ranges ( $\mathrm{kg}$ per vine) are shown in parentheses.

\begin{tabular}{lcccc}
\hline & \multicolumn{2}{c}{ Bobal } & \multicolumn{2}{c}{ Tempranillo } \\
\cline { 2 - 5 } Parameter & without & with & without & with \\
& cover crop & cover crop & cover crop & cover crop \\
\hline Total yield (kg per vine) & $4.87 \mathrm{a}$ & $4.55 \mathrm{a}$ & $4.19 \mathrm{a}$ & $4.09 \mathrm{a}$ \\
& $(3.82-6.65)^{\star}$ & $(3.60-6.48)$ & $(2.90-5.10)$ & $(2.72-5.31)$ \\
Number of clusters/vine & $12 \mathrm{a}$ & $11 \mathrm{a}$ & $19 \mathrm{a}$ & $20 \mathrm{a}$ \\
Cluster weight (g) & $421 \mathrm{a}$ & $406 \mathrm{a}$ & $208 \mathrm{a}$ & $201 \mathrm{a}$ \\
100 berries weight (g) & $279 \mathrm{a}$ & $268 \mathrm{a}$ & $171 \mathrm{a}$ & $167 \mathrm{a}$ \\
Brix & $19.5 \mathrm{a}$ & $20.1 \mathrm{a}$ & $21.1 \mathrm{a}$ & $22.2 \mathrm{a}$ \\
pH & $3.4 \mathrm{a}$ & $3.5 \mathrm{a}$ & $3.5 \mathrm{a}$ & $3.6 \mathrm{a}$ \\
Titratable acidity (g L $\left.{ }^{-1}\right)$ & $6.67 \mathrm{a}$ & $6.55 \mathrm{a}$ & $5.31 \mathrm{a}$ & $5.44 \mathrm{a}$ \\
Total polyphenol index & $67 \mathrm{a}$ & $69 \mathrm{a}$ & $73 \mathrm{a}$ & $71 \mathrm{a}$ \\
Color intensity & $9.6 \mathrm{a}$ & $10.4 \mathrm{a}$ & $7.1 \mathrm{a}$ & $7.5 \mathrm{a}$ \\
\hline
\end{tabular}

Effect of cover crops in grapevine inter-rows and pruning technique on foliar $\mathrm{N}, \mathrm{P}, \mathrm{K}$ concentrations of Tempranillo and Bobal grapevines

Samples of Tempranillo and Bobal leaf were collected at the end of July (2008-2011) when signs of grape veraison emerged, since this phenology stage was the most adequate to assess the nutritional status of grapevines (Navarro et al., 2008). Foliar N, P, K concentrations in the Bobal and Tempranillo vines (Table 4) fell within the ranges of the mineral nutrients considered optimal for adequate grapevine growth and are similar to those measured in four $V$. vinifera cultivars (Navarro et al., 2008). Leaf $\mathrm{N}$ and $\mathrm{K}$ values in both cultivars varied sporadically for management treatments and years, tending to increase regardless of the pruning method. No major differences in $\mathrm{P}$ contents were observed, except for the fact that this element progressively increased in both $\mathrm{Vi}$ tis cultivars from 2008 to 2011. Effects of soil management practices and pruning treatments during four years on vine nutrition were minimum and inconsistent. No 
Table 4 - Effect of distinct soil and vine management practices (2008-2011) on the macroelement leaf content of Bobal and Tempranillo vines. Data are the mean values of three replications. For each cultivar, nutrient and year, the means with the same letter are not significantly different (t-test level $p<0.05)$. * MP = mechanical light pruning; $\mathrm{LCC}=$ leguminous cover crop; TT = traditional tillage; $\mathrm{TP}=$ traditional severe pruning.

\begin{tabular}{|c|c|c|c|c|c|}
\hline \multirow{2}{*}{$\begin{array}{l}\text { Element } \\
\left(\mathrm{g} \mathrm{kg}^{-1}\right)\end{array}$} & \multirow{2}{*}{ Treatments* } & \multicolumn{2}{|c|}{ Bobal } & \multicolumn{2}{|c|}{ Tempranillo } \\
\hline & & 2008 & 2011 & 2008 & 2011 \\
\hline \multirow[t]{4}{*}{ Nitrogen } & $\mathrm{T} 1$ (MP+LCC) & $19.3 a b$ & $24.7 \mathrm{a}$ & $20.1 \mathrm{a}$ & $24.5 a b$ \\
\hline & $\mathrm{T} 2(\mathrm{MP}+\mathrm{TT})$ & $18.9 a$ & $25.0 \mathrm{a}$ & $19.9 \mathrm{a}$ & $24.2 \mathrm{a}$ \\
\hline & $\mathrm{T} 3(\mathrm{TP}+\mathrm{LCC})$ & $20.4 b$ & $26.0 \mathrm{a}$ & $21.0 \mathrm{a}$ & $27.3 b$ \\
\hline & $\mathrm{T} 4(\mathrm{TP}+\mathrm{TT})$ & $19.5 a b$ & $23.9 \mathrm{a}$ & $20.2 \mathrm{a}$ & $26.0 \mathrm{ab}$ \\
\hline \multicolumn{2}{|c|}{ N variation range (2008-2011) } & \multicolumn{2}{|c|}{$18.0-26.4$} & \multicolumn{2}{|c|}{$19.0-27.5$} \\
\hline \multirow[t]{4}{*}{ Phosphorus } & $\mathrm{T} 1(\mathrm{MP}+\mathrm{LCC})$ & $1.8 \mathrm{a}$ & $2.7 \mathrm{a}$ & $1.8 \mathrm{a}$ & $2.4 \mathrm{a}$ \\
\hline & $\mathrm{T} 2(\mathrm{MP}+\mathrm{TT})$ & $1.9 \mathrm{a}$ & $2.5 \mathrm{a}$ & $2.0 \mathrm{a}$ & $2.4 \mathrm{a}$ \\
\hline & $\mathrm{T} 3(\mathrm{TP}+\mathrm{LCC})$ & $1.7 \mathrm{a}$ & $3.0 \mathrm{a}$ & $2.0 \mathrm{a}$ & $2.6 a$ \\
\hline & $\mathrm{T} 4(\mathrm{TP}+\mathrm{TT})$ & $1.6 \mathrm{a}$ & $2.9 \mathrm{a}$ & $2.3 \mathrm{a}$ & $2.8 \mathrm{a}$ \\
\hline \multicolumn{2}{|c|}{ P variation range (2008-2011) } & \multicolumn{2}{|c|}{$1.5-3.1$} & \multicolumn{2}{|c|}{$1.7-2.9$} \\
\hline \multirow[t]{4}{*}{ Potassium } & $\mathrm{T} 1$ (MP+LCC) & $7.9 \mathrm{a}$ & $13.9 \mathrm{a}$ & $11.5 \mathrm{a}$ & $19.0 \mathrm{a}$ \\
\hline & $\mathrm{T} 2(\mathrm{MP}+\mathrm{TT})$ & $8.1 \mathrm{ab}$ & $18.7 \mathrm{~b}$ & $12.5 \mathrm{a}$ & 19.7 a \\
\hline & $\mathrm{T} 3(\mathrm{TP}+\mathrm{LCC})$ & $9.8 \mathrm{bc}$ & $14.3 \mathrm{a}$ & $13.0 \mathrm{a}$ & $17.6 \mathrm{a}$ \\
\hline & $\mathrm{T} 4$ (TP+TT) & $10.0 \mathrm{c}$ & $13.7 \mathrm{a}$ & $13.5 \mathrm{a}$ & $18.3 \mathrm{a}$ \\
\hline \multicolumn{2}{|c|}{ K variation range (2008-2011) } & \multicolumn{2}{|c|}{$7.7-18.9$} & \multicolumn{2}{|c|}{$11.0-19.9$} \\
\hline
\end{tabular}

differences were detected in foliar $\mathrm{N}, \mathrm{P}$ and $\mathrm{K}$ values linked either to the presence or to absence of legumes in the grapevine inter-rows or the application of severe or light pruning. Our results are in line with those reported by Main and Morris (2008) for Cynthiana grapevines, who observed that pruning had a slight influence on this cultivar since the authors found only minor differences in vine nutrition and fruit composition between the four pruning methods applied to the vineyard.

Recently, we determined the effects of severe or light pruning on Bobal and Tempranillo vines by evaluating vine vigor and yield as well as grape and wine characteristics (Pérez-Bermúdez et al., 2015). In both vineyards with soil tillage, light-pruned vines produced more clusters, smaller berries and grape yield increased significantly (30\%). Although these vines tended to overcrop, no detrimental effects of light pruning were observed on grape characteristics and wines. Therefore, we know that mechanical light pruning did not alter $\mathrm{N}, \mathrm{P}$ and $\mathrm{K}$ values in Bobal and Tempranillo vines (Table 4), despite the larger number of retained buds (40-48 buds/vine vs. $12-16$ buds/vine in lightly or severely pruned plants, respectively) that produced more clusters. An altered nutritional vine status might have led to not only altered grapes, which are phloematic sinks for nutritive elements, but also to defective wines.

In conclusion, cover cropping combined with severe or light pruning had little impact on the soil and nutritional status of Bobal and Tempranillo vines. The differences observed between $\mathrm{N}$-fixing cover crops and bare soils suggest that legumes positively affected soil $\mathrm{N}$ and, especially, SOM contents. The minimal effects on soils observed in this short-term study, which had no major influence on vine nutrition and yield or on juice composition, indicate the necessity to conduct long-term studies to assess SOC and $\mathrm{N}$ accumulation processes in mature vineyards.

\section{Acknowledgments}

The Generalitat Valenciana (Project 2007TAHVAL0074) and a research agreement with Cajamar (Requena) have supported this work, which has been performed within the Programme VLC/Campus, Microcluster IViSoCa (Innovation for a Sustainable Viticulture and Quality). We appreciate the technical assistance provided by Isaac Argiles, Benjamín de Andrés, Víctor Paules and the Central Service for Experimental Research (SCSIE) of the University of Valencia. We also thank Helen L. Warburton for checking the English.

\section{References}

Archer, E.; Schalkwyk, D. van. 2007. The effect of alternative pruning methods on the viticultural and oenological performance of some wine grape varieties. South African Journal of Enology and Viticulture 28: 107-139.

Caspari, H.W.; Neal, S.; Naylor, A. 1997. Cover crop management in vineyards to enhance deficit irrigation in a humid climate. Acta Horticulturae 449: 313-320.

Celette, F.; Findeling, A.; Gary, C. 2009. Competition for nitrogen in an unfertilized intercropping system: the case of an association of grapevine and grass cover in a Mediterranean climate. European Journal of Agronomy 30: 41-51.

Celette, F.; Gary, C. 2013. Dynamics of water and nitrogen stress along the grapevine cycle as affected by cover cropping. European Journal of Agronomy 45: 142-152.

Clingeleffer, P.R. 2010. Plant management research: status and what it can offer to address challenges and limitations. Australian Journal of Grape and Wine Research 16: 25-32.

Food and Agriculture Organization [FAO]. 2014. World Reference Base for Soil Resources 2014: International Soil Classification System for Naming Soils and Creating Legends for Soil Maps. FAO, Rome, Italy. (World Soil Resources Reports, 106). 
Fourie, J.C.; Louw, P.J.E.; Agenbag, G.A. 2006. Cover crop management in a Chardonnay/99 Richter vineyard in the coastal region, South Africa. 2. Effect of different cover crops and cover crop management practices on grapevine performance. South African Journal of Enology and Viticulture 27: 178-186.

Guerra, B.; Steenwerth, K. 2012. Influence of floor management technique on grapevine growth, disease pressure, and juice and wine composition: a review. American Journal of Enology and Viticulture 63: 149-164.

International Organization for Standardization [ISO]. 1994. ISO 11260: Determination Of Effective Cation Exchange Capacity and Base Saturation Level Using Barium Chloride Solution. ISO, Geneva, Switzerland.

International Organization for Standardization [ISO]. 1995. ISO 10693: Soil Quality-Determination of Carbonate ContentVolumetric Method. ISO, Geneva, Switzerland.

Main, G.L.; Morris, J.R. 2008. Impact of pruning methods on yield components and juice and wine composition of Cynthiana grapes. American Journal of Enology and Viticulture 59: 179187.

Monteiro, A.; Lopes, C.M. 2007. Influence of cover crop on water use and performance of vineyard in Mediterranean Portugal. Agriculture, Ecosystems and Environment 121: 336-342.

Navarro, S.; León, M.; Roca-Pérez, L.; García-Férriz, L.; PérezBermúdez, P.; Gavidia, I. 2008. Characterisation of Bobal and Crujidera grape cultivars, in comparison with Tempranillo and Cabernet Sauvignon: evolution of leaf macronutrients and berry composition during grape ripening. Food Chemistry 108: 182-190.

Olsen, S.R.; Cole, C.V.; Watanabe, F.S.; Dean, L.A. 1954. Estimation of available phosphorus in soils by extraction with sodium bicarbonate. U.S. Department of Agriculture, Washington, DC, USA. (Circular, 939).

Peregrina, F.; Pérez-Álvarez, E.M.; García-Escudero, E. 2014. Soil microbiological properties and its stratification ratios for soil quality assessment under different cover crop management systems in a semiarid vineyard. Journal of Plant Nutrition and Soil Science 177: 548-559.
Pérez-Bermúdez, P.; Olmo, M.; Gil, J.; García-Ferriz, L.; Olmo, C.; Boluda, R.; Gavidia, I. 2015. Effects of traditional and light pruning on viticultural and oenological performance of Bobal and Tempranillo vineyards. Journal International des Sciences de la Vigne et du Vin 49: 145-154.

Reynolds, A.G.; Wardle, D.A. 2001. Evaluation of minimal pruning upon vine performance and berry composition of Chancellor. American Journal of Enology and Viticulture 52: 45-48.

Roca-Pérez, L.; Pérez-Bermúdez, P.; Gavidia, I.; Boluda, R. 2005. Relationships among soil characteristics, plant macronutrients and cardenolide accumulation in natural populations of Digitalis obscura. Journal of Plant Nutrition and Soil Science 168: 1-7.

Steenwerth, K.; Belina, K.M. 2008a. Cover crops enhance soil organic matter, carbon dynamics and microbiological function in a vineyard agroecosystem. Applied Soil Ecology 40: 359-369.

Steenwerth, K.; Belina, K.M. 2008b. Cover crops and cultivation: impacts on soil $\mathrm{N}$ dynamics and microbiological function in a Mediterranean vineyard agroecosystem. Applied Soil Ecology 40: 370-380.

Steenwerth, K.L.; McElrone, A.J.; Calderón-Orellana, A.; Hanifin, R.C.; Storm, C.; Collatz, W.; Manuck, C. 2013. Cover crops and tillage in a mature Merlot vineyard show few effects on grapevines. American Journal of Enology and Viticulture 64: 515-521.

Sweet, R.M.; Schreiner, R.P. 2010. Alleyway cover crops have little influence on Pinot noir grapevines (Vitis vinifera L.) in two western Oregon vineyards. American Journal of Enology and Viticulture 61: 240-252.

Tesic, D.; Keller, M.; Hutton, R.J. 2007. Influence of vineyard floor management practices on grapevine vegetative growth, yield, and fruit composition. American Journal of Enology and Viticulture 58: 1-11.

Xi, Z.M.; Tao, Y.S.; Zhang, L.; Li, H. 2011. Impact of cover crops in vineyard on the aroma compounds of Vitis vinifera L. cv. Cabernet Sauvignon wine. Food Chemistry 127: 516-522. 